\title{
Reduced dietary omega- 3 fatty acids intake is associated with sarcopenia in elderly patients with type 2 diabetes: a cross-sectional study of KAMOGAWA-DM cohort study
}

\author{
Takuro Okamura, ${ }^{1}$ Yoshitaka Hashimoto, ${ }^{1, *}$ Akane Miki, ${ }^{1}$ Ayumi Kaji, ${ }^{1}$ Ryosuke Sakai,, Keiko Iwai, ${ }^{1}$ \\ Takafumi Osaka, ${ }^{1}$ Emi Ushigome, ${ }^{1}$ Masahide Hamaguchi, ${ }^{1,2}$ Masahiro Yamazaki ${ }^{1}$ and Michiaki Fukui ${ }^{1}$ \\ 1Department of Endocrinology and Metabolism, Kyoto Prefectural University of Medicine, Graduate School of Medical Science, \\ 465, Kajii-cho, Kamigyo-ku, Kyoto 602-8566, Japan \\ ${ }^{2}$ Department of Diabetology, Kameoka Municipal Hospital, Kameoka, Kyoto 621-0826, Japan
}

(Received 19 September, 2019; Accepted 2 October, 2019; Published online 6 March, 2020)

\begin{abstract}
Omega-3 fatty acids intake is important to maintain muscle mass. However, the relationship between omega-3 fatty acids intake and sarcopenia in elderly patients with type 2 diabetes has been unclear. We used the brief-type self-administered diet history questionnaire for the assessment of habitual food and nutrient intake. Body composition of patients was evaluated using bioimpedance analysis. To investigate the effect of energy intake on the presence of sarcopenia, we performed logistic regression analyses. Among the patients, 45 patients $(13.2 \%)$ were diagnosed as sarcopenia. Patients with sarcopenia were aged [74.2 (5.7) vs 71.4 (5.9) years, $p=0.003$ ] and lower body mass index [21.2 (3.5) vs $24.3(4.6) \mathrm{kg} / \mathrm{m}^{2}, p<0.001$ ] than those without. In addition, omega-3 fatty acids intake of patients with sarcopenia was lower than that without $[2.6(1.0)$ vs $3.0(1.2) \mathrm{kcal} / \mathrm{day}, p=0.046]$. Omega-3 fatty acids intake was negatively associated with the presence of sarcopenia (odds ratio: $0.29,95 \%$ confidence interval: $0.14-0.60, p<0.001$ ) after adjusting for age, sex, exercise, smoking status, diabetes duration, hemoglobin A1c, energy intake, protein intake, fat intake and omega- 3 fatty acids intake. Omega-3 fatty acids intake was negatively associated with the presence of sarcopenia in elderly patients with type 2 diabetes.
\end{abstract}

Key Words: sarcopenia, muscle mass, omega-3 fatty acids, nutrition, type 2 diabetes

$\mathrm{N}$ umber of elderly patients with type 2 diabetes is rapidly increasing, and they often have geriatric syndrome such as sarcopenia and frailty. ${ }^{(1)}$ Loss of muscle mass and degradation of muscle with aging is called sarcopenia, which leads to motor function disorder, falls, fractures and difficulty in sending daily life..$^{(2,3)}$ It has also been reported that sarcopenia increases the risk of death. ${ }^{(4)}$ To maintain the muscle mass, it is necessary to take sufficient protein, ${ }^{(5)}$ and there is a report that healthy elderly people should take $1 \mathrm{~g}$ of protein per body weight $(\mathrm{kg})$ to promote muscle protein anabolism and increase muscle mass. ${ }^{(6)}$ In fact, we previously reported that protein intake is associated with muscle mass. ${ }^{(7)}$

On the other hand, some previous studies reported that polyunsaturated fatty acids such as omega- 3 and omega- 6 fatty acids might play a role in not only prevention of cardiovascular disease and cancer $^{(8)}$ but also muscle hypertrophy. ${ }^{(9)}$ Especially, omega-3 fatty acids was reported to decrease inflammation through interference with arachidonic acid metabolism and preserve skeletal muscle mass in elderly people. ${ }^{(10,11)}$ Omega-3 fatty acids supple- mentation increased muscle mass and strength in elderly healthy individuals. ${ }^{(12,13)}$ While several previous reports demonstrated that dietary omega-3 fatty acids intake was associated with muscle strength, ${ }^{(10,14,15)}$ few studies reported the association between dietary omega-3 fatty acids intake and muscle mass. ${ }^{(9)}$ Thus, we aimed to investigate the association between dietary omega-3 fatty acids intake and sarcopenia diagnosed by both muscle strength and mass in elderly patients with type 2 diabetes.

\section{Materials and Methods}

Study patients. KAMOGAWA-DM cohort study is an ongoing prospective cohort study from $2014 .{ }^{(16)}$ We extracted the elderly type 2 diabetes patients, age $\geq 65$ years and without physical inactivity, who were recruited from the outpatient clinics at the Kyoto Prefectural University of Medicine and Kameoka Municipal Hospital from August 2015 to September 2017 in this cross-sectional study. We excluded patients with diabetic nephropathy stage 3 or more, ${ }^{(17)}$ inflammatory disease, malignancy, and endocrine disease. ${ }^{(4)}$ In addition, we also excluded patients with class NYHA II-IV cardiac insufficiency ${ }^{(18)}$ and severe chronic obstructive pulmonary disease ${ }^{(19)}$ because these conditions would influence in appetite and physical activity. Approval for the study was obtained from the local research ethics committee, and written informed consent was obtained from all patients.

Estimation and assessment of usual food and nutrient intake. The brief-type self-administered diet history questionnaire (BDHQ) was used for the assessment of usual food and nutrient intake in this study. ${ }^{(20)}$ The details of BDHQ were expressed elsewhere. ${ }^{(20)}$ Briefly, BDHQ estimates the dietary intake of 58 items in the past month using five sections: (i) daily intake of rice, type of rice, and miso soup; (ii) frequency of fortysix food and nonalcoholic beverage items; (iii) usual cooking methods; (iv) frequency of drinking alcoholic beverages and amount per drink for five alcoholic beverages; and (v) general dietary behavior. ${ }^{(20)}$ Estimates of the intakes of energy, carbohydrate, protein and fat or the intakes of the 58 food items were calculated by an ad hoc computer algorithm for the BDHQ based on Standard Tables of Food Composition in Japan. ${ }^{(21)} \mathrm{We}$ estimated dietary total energy (kcal/day), carbohydrate (g/day),

*To whom correspondence should be addressed.

E-mail: y-hashi@koto.kpu-m.ac.jp 
total protein (g/day), fat (g/day), alcohol (g/day), omega-3 fatty acids intake (g/day) and omega- 6 fatty acids intake (g/day), using this calculation program of BDHQ. We also excluded the patient who reported extremely low (under $600 \mathrm{kcal}$ ) or high (over $4,000 \mathrm{kcal})$ energy intake. ${ }^{(22)}$

Measurement of body composition determined by bioelectric impedance. We evaluated the body composition of patients using the InBody 720 (InBody Japan, Tokyo, Japan), which analyzes body composition with a multifrequency impedance. ${ }^{(23)}$ Several previous studies demonstrated that the multifrequency impedance analyzer shows a good correlation with the dualenergy X-ray absorptiometry method and was validated. ${ }^{(24)}$ We got the data of body weight $(\mathrm{BW}, \mathrm{kg})$, body fat mass $(\mathrm{kg})$, skeletal muscle mass $(\mathrm{kg})$ and appendicular muscle mass $(\mathrm{kg})$. Additionally, we calculated skeletal muscle mass index (SMI, $\mathrm{kg} / \mathrm{m}^{2}$ ) by dividing appendicular muscle mass $(\mathrm{kg})$ by the square of the height $(\mathrm{m}),{ }^{(25,26)}$ and defined body mass index (BMI) as body weight ( $\mathrm{kg}$ ) divided by the square of the height $(\mathrm{m})$.

Standardized questionnaire for lifestyle factors. A standardized questionnaire was performed to all patients. We divided the patients into nonsmoker, ex-smoker and current smoker. On the questionnaire, patients reported the kind and frequency of their participation in sports or recreational activities. ${ }^{(27)}$ We categorized the patients, who performed any kind of sport regularly at least once a week, as regular exercisers. ${ }^{(28)}$

Data collection. The concentrations of several factors, including fasting plasma glucose, creatinine and C-peptide were measured, using venous blood, after an overnight fast. Hemoglobin Alc (HbAlc) was analyzed using high-performance liquid chromatography and was showed as a National Glycohemoglobin Standardization Program unit. We used the Japanese Society of Nephrology equation for estimated glomerular filtration rate (eGFR): eGFR $\left(\mathrm{ml} / \mathrm{min} / 1.73 \mathrm{~m}^{2}\right)=194 \times$ serum creatinine $\mathrm{c}^{-1.094} \times$ age $^{-0.287}(\times 0.739$ for women $) .{ }^{(29)}$ In addition, patients reported the kind of oral hypoglycemic agent and the presence of insulin use on the questionnaire.

Definition of sarcopenia. Sarcopenia was diagnosed with grip strength and SMI based on Japan Society of Hepatology guidelines for sarcopenia. ${ }^{(30)}$ We measured grip strength of patients using a Smedley grip dynamometer, and set the cut-off values to $<26 \mathrm{~kg} / \mathrm{m}^{2}$ for men and $18 \mathrm{~kg} / \mathrm{m}^{2}$ for women. Moreover, we set the cut-off values of SMI to $<7.0 \mathrm{~kg} / \mathrm{m}^{2}$ for men and $5.7 \mathrm{~kg} / \mathrm{m}^{2}$ for women. We diagnosed patients with both of two benchmarks as sarcopenia.
Statistical analysis. We preformed statistical analyses using JMP ver. 12.0 software (SAS Institute Inc., Cary, NC) and considered that a $p$ value $<0.05$ was statistically significant. Mean or frequencies of potential confounding variables were calculated, and continuous variables were presented as the mean (SD). We divided the patients into tertile according to dietary omega-3 fatty acids intake: the lowest group (men; $<2.3 \mathrm{~g} /$ day, women; $<2.1 \mathrm{~g} /$ day), the middle group (men; $\geq 2.3,<3.3 \mathrm{~g} /$ day, women; $\geq 2.1,<3.1 \mathrm{~g} /$ day), and the highest group (men; $\geq 3.3 \mathrm{~g} /$ day, women; $\geq 3.1 \mathrm{~g} /$ day). Categorial variables were compared among the groups by Pearson's chi-square test, and continuous variables were compared by one-way ANOVA and Tukey HSD test, respectively. Odds ratios (ORs) and 95\% confidence intervals (CIs) of several factors on the presence of sarcopenia were calculated and we considered following factors as independent variables for multivariate logistic regression analyses: age, sex, exercise, smoking status, diabetes duration, HbAlc, energy intake, protein intake, fat intake ${ }^{(16)}$ and omega-3 fatty acids intake.

\section{Results}

In this study, 390 patients (207 men and 183 women) with type 2 diabetes received BDHQ. Among them, a total of 359 patients completed the questionnaire, yielding a collection rate of $92.1 \%$. We excluded 6 patients with incomplete data of covariates, 3 patients with diabetic nephropathy stage 3 or more and 8 patients with hyper- and hypo-nutrition. Finally, the study population was 342 patients (180 men and 162 women) (Fig. 1). There were no patients with class NYHA II-IV cardiac insufficiency and severe chronic obstructive pulmonary disease.

Clinical characteristics of 342 patients with type 2 diabetes are shown in Table 1. The average (SD) of age and HbAlc were 74.2 (5.7) years and 7.8 (1.3) \% in patients with sarcopenia, and 71.4 (5.9) years and $7.7(1.7) \%$ in patients without sarcopenia, respectively. In addition, the average (SD) of omega- 3 fatty acids intake in patients with sarcopenia was lower than that in patients without [2.6 (1.0) vs 3.0 (1.2) g/day, $p=0.046]$.

Unadjusted and adjusted ORs and $95 \%$ CIs of the presence of sarcopenia are shown in Table 2 . We divided the patients into tertile according to omega-3 fatty acids intake, and the lowest group showed a significant association with sarcopenia compared to the highest group in univariate logistic regression analyses (OR: 3.04, 95\% CI: $1.05-8.75, p=0.039$ ). In addition, in the multivariate logistic regression analyses, omega- 3 fatty acids

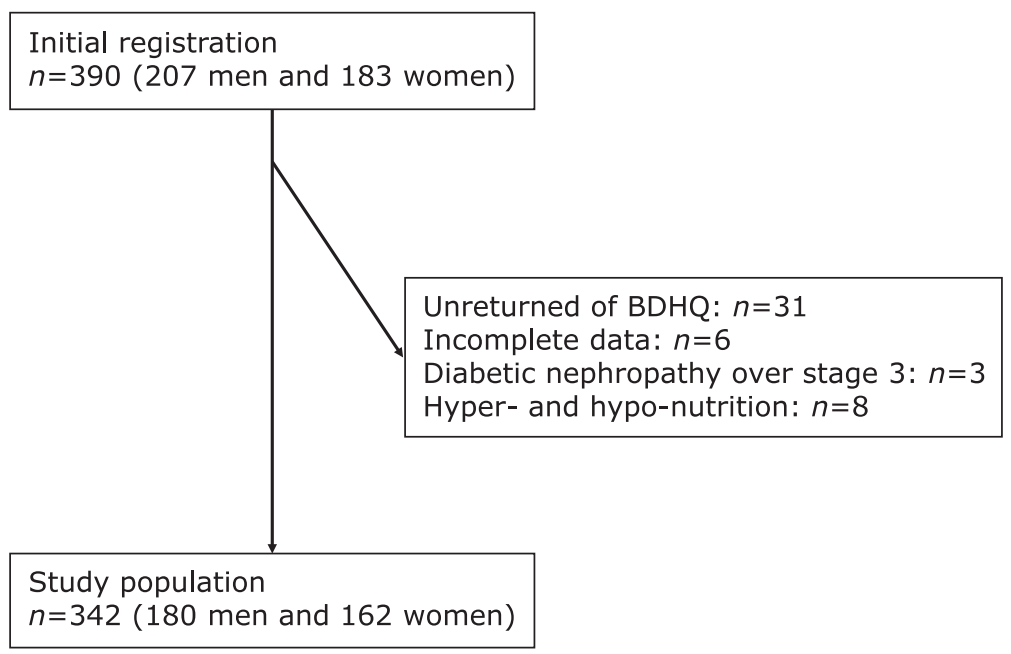

Fig. 1. Study flow diagram for the registration of patients. 
Table 1. Clinical characteristics of study patients

\begin{tabular}{|c|c|c|c|c|}
\hline & $\begin{array}{c}\text { Total } \\
(n=342)\end{array}$ & $\begin{array}{l}\text { Patients with sarcopenia } \\
\qquad(n=45)\end{array}$ & $\begin{array}{l}\text { Patients without sarcopenia } \\
\qquad(n=297)\end{array}$ & $p$ value \\
\hline Sex (men/women) & $180 / 162$ & $21 / 24$ & $159 / 138$ & 0.39 \\
\hline Age (year) & $71.8(6.0)$ & $74.2(5.7)$ & $71.4(5.9)$ & 0.003 \\
\hline Body weight $(\mathrm{kg})$ & $60.2(13.0)$ & $50.9(9.4)$ & $61.7(12.9)$ & $<0.001$ \\
\hline Body mass index $\left(\mathrm{kg} / \mathrm{m}^{2}\right)$ & $23.9(4.5)$ & $21.2(3.5)$ & $24.3(4.6)$ & $<0.001$ \\
\hline Skeletal muscle mass $(\mathrm{kg})$ & $22.4(4.7)$ & $18.3(3.1)$ & $23.0(4.6)$ & $<0.001$ \\
\hline Appendicular muscle mass $(\mathrm{kg})$ & $16.9(4.1)$ & $13.5(2.8)$ & $17.4(4.0)$ & $<0.001$ \\
\hline Skeletal muscle mass index $\left(\mathrm{kg} / \mathrm{m}^{2}\right)$ & $6.6(1.0)$ & $5.6(0.6)$ & $6.8(1.0)$ & $<0.001$ \\
\hline Grip Strength (kg) & $26.4(8.1)$ & $16.7(5.3)$ & $27.9(7.4)$ & $<0.001$ \\
\hline Body fat mass $(\mathrm{kg})$ & $17.4(7.3)$ & $14.8(6.0)$ & $17.8(7.4)$ & 0.009 \\
\hline Smoking (non-/ex-/current smoker) & $267 / 54 / 21$ & $1,937 / 5 / 3$ & $230 / 49 / 18$ & 0.652 \\
\hline Regular exerciser (no/yes) & $263 / 79$ & $38 / 7$ & $72 / 225$ & 0.181 \\
\hline Disease duration (year) & $11.2(11.9)$ & $13.9(16.7)$ & $10.9(11.2)$ & 0.163 \\
\hline Plasma glucose (mM) & $8.4(3.5)$ & $7.8(2.9)$ & $8.5(3.5)$ & 0.195 \\
\hline Hemoglobin A1c (\%) & $7.7(1.6)$ & $7.8(1.3)$ & $7.7(1.7)$ & 0.68 \\
\hline eGFR $\left(\mathrm{ml} / \mathrm{min} / 1.73 \mathrm{~m}^{2}\right)$ & $67.7(17.2)$ & $69.6(16.8)$ & $67.4(17.3)$ & 0.417 \\
\hline C-peptide (nmol/L) & $2.0(1.4)$ & $1.9(1.6)$ & $2.0(1.3)$ & 0.739 \\
\hline C-reactive protein (mg/dl) & $0.3(0.9)$ & $0.1(0.1)$ & $0.3(0.9)$ & 0.201 \\
\hline Sulfonylureas $(-/+)$ & $265 / 77$ & $33 / 12$ & $232 / 65$ & 0.342 \\
\hline Glinides $(-/+)$ & $320 / 22$ & $40 / 5$ & $280 / 17$ & 0.148 \\
\hline$\alpha$-Glucosidase inhibitors $(-/+)$ & $296 / 46$ & $45 / 0$ & $251 / 46$ & 0.01 \\
\hline Metformin $(-/+)$ & $298 / 44$ & $40 / 5$ & $258 / 39$ & 0.794 \\
\hline Thiazolidine $(-/+)$ & $326 / 16$ & $45 / 0$ & $281 / 16$ & 0.1 \\
\hline Dipeptidyl peptidase-4 inhibitor $(-/+)$ & $320 / 122$ & $27 / 18$ & 193/104 & 0.661 \\
\hline Glucagon like peptide-1receptor agonist $(-/+)$ & $322 / 20$ & $42 / 3$ & $280 / 17$ & 0.762 \\
\hline Sodium-glucose cotransporter 2 inhibitors $(-/+)$ & $337 / 5$ & $45 / 0$ & $292 / 5$ & 0.839 \\
\hline Insulin treatment $(-/+)$ & $280 / 62$ & $33 / 12$ & $247 / 50$ & 0.591 \\
\hline Energy intake (kcal/day) & $1,774.0(584.1)$ & $1,645.0(493.8)$ & $1,792.6(594.5)$ & 0.052 \\
\hline Protein intake (g/day) & $74.1(29.1)$ & $68.7(21.5)$ & $74.9(30.0)$ & 0.193 \\
\hline Fat intake (g/day) & $52.1(20.7)$ & $46.6(16.5)$ & $52.9(21.2)$ & 0.063 \\
\hline Carbohydrate intake (g/day) & $230.1(85.5)$ & $226.1(79.5)$ & $230.6(86.4)$ & 0.743 \\
\hline Omega-3 fatty acid (g/day) & $2.9(1.4)$ & $2.6(1.0)$ & $3.0(1.2)$ & 0.046 \\
\hline Omega- 6 fatty acid (g/day) & $9.9(4.0)$ & $8.8(3.4)$ & $10.1(4.0)$ & 0.045 \\
\hline Omega- 6 fatty acid/omega-3 fatty acid ratio & $3.7(1.2)$ & $3.6(1.4)$ & $3.7(1.1)$ & 0.595 \\
\hline Alcohol intake (g/day) & $9.8(18.5)$ & $3.8(8.5)$ & $10.6(19.4)$ & 0.026 \\
\hline
\end{tabular}

Data was expressed as mean (SD) or number. Wilcoxon test for continuous variables or the chi-square test for categorical variables was performed to assess statistical significance of differences between groups. eGFR, estimated glomerular filtration rate.

Table 2. Univariate and multivariate logistic regression analyses for sarcopenia

\begin{tabular}{|c|c|c|c|c|c|c|c|c|}
\hline & \multicolumn{2}{|l|}{ Model 1} & \multicolumn{2}{|l|}{ Model 2} & \multicolumn{2}{|l|}{ Model 3} & \multicolumn{2}{|l|}{ Model 4} \\
\hline & $\begin{array}{l}\text { Odds ratio } \\
(95 \% \mathrm{Cl})\end{array}$ & $p$ value & $\begin{array}{l}\text { Odds ratio } \\
(95 \% \mathrm{Cl})\end{array}$ & $p$ value & $\begin{array}{l}\text { Odds ratio } \\
(95 \% \mathrm{Cl})\end{array}$ & $p$ value & $\begin{array}{l}\text { Odds ratio } \\
(95 \% \mathrm{Cl})\end{array}$ & $p$ value \\
\hline Age (year) & - & - & - & - & $1.10(1.02-1.19)$ & 0.013 & $1.11(1.03-1.20)$ & 0.007 \\
\hline Regular exerciser & - & - & - & - & $0.95(0.34-2.68)$ & 0.921 & $0.90(0.32-2.53)$ & 0.834 \\
\hline Ex smoker & - & - & - & - & $2.16(0.52-8.93)$ & 0.288 & $1.90(0.47-7.68)$ & 0.366 \\
\hline Current smoker & - & - & - & - & $2.90(0.51-16.63)$ & 0.232 & $2.43(0.44-13.61)$ & 0.311 \\
\hline Energy intake (kcal/kg BW/day) & - & - & - & - & $0.98(0.90-1.06)$ & 0.602 & $1.01(0.94-1.08)$ & 0.68 \\
\hline Protein intake (kcal/kg BW/day) & - & - & - & - & $3.34(0.40-28.14)$ & 0.267 & $0.62(0.09-4.29)$ & 0.971 \\
\hline Fat intake (kcal/kg BW/day) & - & - & - & - & $5.49(0.49-61.20)$ & 0.164 & $3.65(0.50-26.6)$ & 0.478 \\
\hline Omega-3 fatty acids intake (g/day) & $0.74(0.54-1.01)$ & 0.043 & & & $0.29(0.14-0.60)$ & $<0.001$ & - & - \\
\hline \multicolumn{9}{|l|}{ Tertiles } \\
\hline $\begin{array}{l}\text { The lowest (men; }<2.3 \mathrm{~g} / \mathrm{day} \text {, } \\
\text { women; }<2.1 \mathrm{~g} / \text { day) }\end{array}$ & - & - & $3.04(1.05-8.75)$ & 0.039 & - & - & $9.56(1.50-61.01)$ & 0.017 \\
\hline
\end{tabular}

Model 1 and 2 was unadjusted. Model 3 was adjusted for age, sex, exercise, smoking status, diabetes duration, Hemoglobin A1c, energy intake, protein intake, fat intake and omega-3 fatty acids intake. Model 4 was adjusted for age, sex, exercise, smoking status, diabetes duration, Hemoglobin A1c, energy intake, protein intake, fat intake and omega-3 fatty acids intake tertile. 
intake based on continuous variables was negatively associated with the presence of sarcopenia $(0.29,0.14-0.60, p<0.001)$, and the lowest and the middle group of omega-3 fatty acids intake showed a significant association with the presence of sarcopenia compared to the highest group (the lowest; 9.56, 1.50-61.01, $p=0.017$, the middle; 5.91, $1.16-30.08, p=0.032$ ).

\section{Discussion}

We demonstrated that reduced dietary omega-3 fatty acids intake was associated with the presence of sarcopenia in elderly patients with type 2 diabetes. Although several studies showed that some fatty acids such as omega-3 fatty acids or maslinic acid intake was associated with muscle strength and muscle mass in healthy elderly people ${ }^{(8,9,12-15,31)}$ to our knowledge, the present study is the first survey to identify the association between omega-3 fatty acids intake and sarcopenia in elderly patients with type 2 diabetes.

The possible explanations of the association between reduced omega-3 fatty acids intake and sarcopenia are as follows. To reduce the inflammation is important for prevention of sarcopenia. ${ }^{(32)}$ Omega-3 fatty acids, which form a series of eicosanoids different from omega-6 fatty acids, compete with the major enzymes involved in eicosanoid formation from arachidonic acid, i.e., cyclooxygenase and lipoxygenase. ${ }^{(33,34)}$ However, these eicosanoids have lower bioactivity and less inflammation than eicosanoids formed from arachidonic acid metabolism. ${ }^{(35)}$ Therefore, omega-3 fatty acids may reduce inflammation and reserve skeletal muscle mass through interference of arachidonic acid metabolism. ${ }^{(36)}$

In addition, Smith et al. ${ }^{(37)}$ reported that omega-3 fatty acids supplementation such as eicosapentaenoic acid and docosahexaenoic acid for 8 weeks stimulated muscle protein synthesis and be useful for both prevention and treatment of sarcopenia in elderly individuals. With the supplementation, phosphorylation of mammallian target of rapamycin (mTOR) and p70s6k, which were involved in muscle protein synthesis, was activated without activation of inflammatory cytokines. These activities were thought to occur by incorporating omega-3 fatty acids into myocyte membranes, which resulted in activating protein kinase $\mathrm{C}$ located upstream of mTOR and p70s6k. ${ }^{(38)}$ Additionally, omega-3 fatty acids attenuate oxidative stress by suppressing forkhead boxcontaining protein, $\mathrm{O} 1$ (foxo1) pathway, ${ }^{(39)}$ and suppressing foxo1 leads to suppression of muscle atrophy. ${ }^{(40)}$ In summary, omega-3 fatty acids may stimulate protein synthesis.

Omega-3 fatty acids may also affect membrane composition of nervous tissue, which results in a favorable effect on nervous system function. ${ }^{(41)}$ Rodacki et al. ${ }^{(14)}$ reported that elderly women who were supplemented fish oil, which is rich in omega- 3 fatty acids, with strength training program showed greater improvements in the neuromuscular system such as muscle strength and functional capacity than those who only performed strength training program without fish oil supplementation. Taken together, omega-3 fatty acids may work through several different mechanisms to increase muscle mass and to improve skeletal muscle strength through promoting neuromuscular function.

Our study has some limitations. First, the accuracy of diet survey depends on the memorial power of patients, because the data were based on the self-reported questionnaires. However, BDHQ was correlated with energy and protein intake evaluated by the 16-day-weighed dietary record. ${ }^{(20)}$ Second, we used body composition of patients using a mulitifrequency impedance body composition analyzer, although the dual-energy X-ray absorptiometry

\section{References}

1 Kim TN, Park MS, Yang SJ, et al. Prevalence and determinant factors of sarcopenia in patients with type 2 diabetes: the Korean Sarcopenic Obesity Study (KSOS). Diabetes Care 2010; 33: 1497-1499. is a gold standard test for evaluating skeletal muscle mass. However, a mulitifrequency impedance body composition analyzer has good correlation with the dual-energy X-ray absorptiometry. ${ }^{(24)}$ Third, this study was a cross-sectional design; thus, this study did not permit the determination of causality. Additionally, although it has been postulated that diabetes may be an important factor in sarcopenia development, the relationship is unclear since the opposite maybe also true. ${ }^{(42)}$ To clarify these causal relationships, follow up data are necessary. Fourth, we used dichotomous value for exercise, because we did not have detailed data of exercise or physical activity. Lastly, it is unclear whether this result applies to elderly patients with type 2 diabetes other than Japanese.

\section{Conclusions}

In conclusion, reduced dietary omega- 3 fatty acids intake was associated with the presence of sarcopenia in patients with type 2 diabetes. Further prospective studies are needed to better asses the relationship between sarcopenia and omega-3 fatty acids intake in elderly patients with type 2 diabetes.

\section{Acknowledgments}

We thank all of the staff members of the Kyoto Prefectural University of Medicine and Kameoka Municipal Hospital.

\section{Abbreviations}

BDHQ brief-type self-administered diet history questionnaire

BMI body mass index

BW body weight

CI confidence interval

eGFR estimated glomerular filtration rate

foxol forkhead box-containing protein, $\mathrm{O} 1$

HbAlc hemoglobin Alc

OR odds ratio

SMI skeletal muscle index

mTOR mammallian target of rapamycin

\section{Conflict of Interenst}

YH received grants from Asahi Kasei Corporation outside the submitted work. MF received grants from AstraZeneca plc, Astellas Pharma Inc., Nippon Boehringer Ingelheim Co., Ltd., Daiichi Sankyo Co., Ltd., Eli Lilly Japan K.K., Kyowa Hakko Kirin Co., Ltd., Kissei Pharmaceutical Co., Ltd., MSD K.K., Mitsubishi Tanabe Pharma Corp., Novo Nordisk Pharma Ltd., Sanwa Kagaku Kenkyusho Co., Ltd., Sanofi K.K., Ono Pharmaceutical Co., Ltd, and Takeda Pharmaceutical Co., Ltd., outside the submitted work. The sponsors were not involved in the study design; in the collection, analysis, interpretation of data; in the writing of this manuscript; or in the decision to submit the article for publication. The authors, their immediate families, and any research foundations with which they are affiliated have not received any financial payments or other benefits from any commercial entity related to the subject of this article. The authors declare that although they are affiliated with a department that is supported financially by pharmaceutical company, the authors received no current funding for this study, and this does not alter their adherence to all the journal policies on sharing data and materials. The other authors have nothing to disclose.

2 Nakamura A, Osonoi T, Terauchi Y. Relationship between urinary sodium excretion and pioglitazone-induced edema. J Diabetes Investig 2010; 1: 208 211. 
3 Goodpaster BH, Park SW, Harris TB, et al. The loss of skeletal muscle strength, mass, and quality in older adults: the health, aging and body composition study. J Gerontol A Biol Sci Med Sci 2006; 61: 1059-1064.

4 Cruz-Jentoft AJ, Baeyens JP, Bauer JM, et al. Sarcopenia: European consensus on definition and diagnosis: report of the European Working Group on Sarcopenia in Older People. Age Ageing 2010; 39: 412-423.

5 Boirie Y, Morio B, Caumon E, Cano NJ. Nutrition and protein energy homeostasis in elderly. Mech Ageing Dev 2014; 136-137: 76-84.

6 Houston DK, Nicklas BJ, Ding J, et al. Dietary protein intake is associated with lean mass change in older, community-dwelling adults: the Health, Aging, and Body Composition (Health ABC) Study. Am J Clin Nutr 2008; 87: $150-155$.

7 Miki A, Hashimoto Y, Matsumoto S, et al. Protein intake, especially vegetable protein intake, is associated with higher skeletal muscle mass in elderly patients with type 2 diabetes. J Diabetes Res 2017; 2017: 7985728.

8 Manson JE, Cook NR, Lee IM, et al. Marine n-3 fatty acids and prevention of cardiovascular disease and cancer. N Engl J Med 2019; 380: 23-32.

9 Candow DG, Forbes SC, Little JP, Cornish SM, Pinkoski C, Chilibeck PD. Effect of nutritional interventions and resistance exercise on aging muscle mass and strength. Biogerontology 2012; 13: 345-358.

10 Cornish SM, Chilibeck PD. Alpha-linolenic acid supplementation and resistance training in older adults. Appl Physiol Nutr Metab 2009; 34: 49-59.

11 Roubenoff R. Catabolism of aging: is it an inflammatory process? Curr Opin Clin Nutr Metab Care 2003; 6: 295-299.

12 Logan SL, Spriet LL. Omega-3 fatty acid supplementation for 12 weeks increases resting and exercise metabolic rate in healthy community-dwelling older females. PLoS One 2015; 10: e0144828.

13 Smith GI, Julliand S, Reeds DN, Sinacore DR, Klein S, Mittendorfer B. Fish oil-derived n-3 PUFA therapy increases muscle mass and function in healthy older adults. Am J Clin Nutr 2015; 102: 115-122.

14 Rodacki CL, Rodacki AL, Pereira G, et al. Fish-oil supplementation enhances the effects of strength training in elderly women. Am J Clin Nutr 2012; 95: 428-436.

15 Wong TC, Chen YT, Wu PY, et al. Ratio of dietary n-6/n-3 polyunsaturated fatty acids independently related to muscle mass decline in hemodialysis patients. PLoS One 2015; 10: e0140402.

16 Sakai R, Hashimoto Y, Ushigome E, et al. Late-night-dinner is associated with poor glycemic control in people with type 2 diabetes: the KAMOGAWADM cohort study. Endocr J 2018; 65: 395-402.

17 Haneda M, Utsunomiya K, Koya D, et al. A new Classification of Diabetic Nephropathy 2014: a report from Joint Committee on Diabetic Nephropathy. J Diabetes Investig 2015; 6: 242-246.

18 von Haehling S, Doehner W, Anker SD. Nutrition, metabolism, and the complex pathophysiology of cachexia in chronic heart failure. Cardiovasc Res 2007; 73: 298-309.

19 Abbatecola AM, Fumagalli A, Spazzafumo L, et al. Body composition markers in older persons with COPD. Age Ageing 2014; 43: 548-553.

20 Kobayashi S, Murakami K, Sasaki S, et al. Comparison of relative validity of food group intakes estimated by comprehensive and brief-type self-administered diet history questionnaires against $16 \mathrm{~d}$ dietary records in Japanese adults. Public Health Nutr 2011; 14: 1200-1211.

21 Ministry of Education, Culture, Sports, Science and Technology. STANDARD TABLES OF FOOD COMPOSITION IN JAPAN (in Japanese). Tokyo, 2015. Accessed 2 Dec 2018.

22 Bauer J, Biolo G, Cederholm T, et al. Evidence-based recommendations for optimal dietary protein intake in older people: a position paper from the PROT-AGE Study Group. J Am Med Dir Assoc 2013; 14: 542-559.

23 Hashimoto Y, Osaka T, Fukuda T, Tanaka M, Yamazaki M, Fukui M. The relationship between hepatic steatosis and skeletal muscle mass index in men with type 2 diabetes. Endocr J 2016; 63: 877-884.

24 Kim M, Shinkai S, Murayama H, Mori S. Comparison of segmental multi- frequency bioelectrical impedance analysis with dual-energy X-ray absorptiometry for the assessment of body composition in a community-dwelling older population. Geriatr Gerontol Int 2015; 15: 1013-1022.

25 Chen LK, Liu LK, Woo J, et al. Sarcopenia in Asia: consensus report of the Asian Working Group for Sarcopenia. J Am Med Dir Assoc 2014; 15: 95-101.

26 Fielding RA, Vellas B, Evans WJ, et al. Sarcopenia: an undiagnosed condition in older adults. Current consensus definition: prevalence, etiology, and consequences. International working group on sarcopenia. J Am Med Dir Assoc 2011; 12: 249-256.

27 Osaka T, Hashimoto Y, Fukuda T, Tanaka M, Yamazaki M, Fukui M. Relationship between skeletal muscle mass and hepatic fibrosis in patients with type 2 diabetes. Diabetes Metab 2017; 43: 184-186.

28 Hashimoto Y, Hamaguchi M, Kojima T, et al. Modest alcohol consumption reduces the incidence of fatty liver in men: a population-based large-scale cohort study. J Gastroenterol Hepatol 2015; 30: 546-552.

29 Matsuo S, Imai E, Horio M, et al. Revised equations for estimated GFR from serum creatinine in Japan. Am J Kidney Dis 2009; 53: 982-992.

30 Nishikawa H, Shiraki M, Hiramatsu A, Moriya K, Hino K, Nishiguchi $\mathrm{S}$. Japan Society of Hepatology guidelines for sarcopenia in liver disease (1st edition): recommendation from the working group for creation of sarcopenia assessment criteria. Hepatol Res 2016; 46: 951-963.

31 Nagai N, Yagyu S, Hata A, et al. Maslinic acid derived from olive fruit in combination with resistance training improves muscle mass and mobility functions in the elderly. J Clin Biochem Nutr 2019; 64: 224-230.

32 Park S, Na W, Sohn C. Relationship between osteosarcopenic obesity and dietary inflammatory index in postmenopausal Korean women: 2009 to 2011 Korea National Health and Nutrition Examination Surveys. J Clin Biochem Nutr 2018; 63: 211-216.

33 Serhan CN, Clish CB, Brannon J, Colgan SP, Chiang N, Gronert K. Novel functional sets of lipid-derived mediators with antiinflammatory actions generated from omega-3 fatty acids via cyclooxygenase 2-nonsteroidal antiinflammatory drugs and transcellular processing. J Exp Med 2000; 192: 1197-1204.

34 Serhan CN, Chiang N, Van Dyke TE. Resolving inflammation: dual antiinflammatory and pro-resolution lipid mediators. Nat Rev Immunol 2008; 8: 349-361.

35 Calder PC. Omega-3 fatty acids and inflammatory processes: from molecules to man. Biochem Soc Trans 2017; 45: 1105-1115.

36 Smith GI, Atherton P, Reeds DN, et al. Dietary omega-3 fatty acid supplementation increases the rate of muscle protein synthesis in older adults: a randomized controlled trial. Am J Clin Nutr 2011; 93: 402-412.

37 Smith GI, Atherton P, Reeds DN, et al. Omega-3 polyunsaturated fatty acids augment the muscle protein anabolic response to hyperinsulinaemiahyperaminoacidaemia in healthy young and middle-aged men and women. Clin Sci (Lond) 2011; 121: 267-278.

38 Palacios-Pelaez R, Lukiw WJ, Bazan NG. Omega-3 essential fatty acids modulate initiation and progression of neurodegenerative disease. Mol Neurobiol 2010; 41: 367-374.

39 Sakai C, Ishida M, Ohba H, et al. Fish oil omega-3 polyunsaturated fatty acids attenuate oxidative stress-induced DNA damage in vascular endothelial cells. PLoS One 2017; 12: e0187934.

40 Okamura T, Hashimoto Y, Osaka T, Fukuda T, Hamaguchi M, Fukui M. The sodium-glucose cotransporter 2 inhibitor luseogliflozin can suppress muscle atrophy in $\mathrm{Db} / \mathrm{Db}$ mice by suppressing the expression of foxol. J Clin Biochem Nutr 2019; 65: 23-28.

41 Kitajka K, Sinclair AJ, Weisinger RS, et al. Effects of dietary omega-3 polyunsaturated fatty acids on brain gene expression. Proc Natl Acad Sci US A 2004; 101: 10931-10936.

42 Kalyani RR, Corriere M, Ferrucci L. Age-related and disease-related muscle loss: the effect of diabetes, obesity, and other diseases. Lancet Diabetes Endocrinol 2014; 2: 819-829. 